\title{
Immunoglobulin free light chains and GAGs mediate multiple myeloma extracellular vesicles uptake and secondary NfkB nuclear translocation
}

\section{Giuseppe Di Noto ${ }^{1}$, Marco Chiarini ${ }^{2}$, Lucia Paolini ${ }^{1}$, Elena Laura Mazzoldi ${ }^{1}$, Viviana Giustini $^{2}$, Annalisa Radeghieri ${ }^{1}$, Luigi Caimi ${ }^{1}$ and Doris Ricotta ${ }^{1}$ *}

1 Department of Molecular and Translational Medicine, Faculty of Medicine, University of Brescia, Brescia, Italy

${ }^{2}$ CREA, Diagnostic Department, Azienda Ospedaliera Spedali Civili di Brescia, Brescia, Italy

Edited by:

Francesc E. Borras, Fundació Institut d'Investigació en Ciéncies de la Salut Germans Trias i Pujol, Spain

\section{Reviewed by:}

Edit Buzás, Semme/weis University, Hungary

Francesc E. Borras, Fundació Institut d'Investigació en Ciéncies de la Salut Germans Trias i Pujol, Spain

\section{*Correspondence:}

Doris Ricotta, Department of

Molecular and Translational Medicine

Faculty of Medicine, University of

Brescia, 11 Viale Europa, Brescia

25123, Italy

e-mail:doris.ricotta@gmail.com
Multiple myeloma (MM) is a hematological malignancy caused by a microenviromentally aided persistence of plasma cells in the bone marrow. Monoclonal plasma cells often secrete high amounts of immunoglobulin free light chains (FLCs) that could induce tissue damage. Recently, we showed that FLCs are internalized in endothelial and myocardial cell lines and secreted in extracellular vesicles (EVs). MM serum derived EVs presented phenotypic differences if compared with monoclonal gammopathy of undetermined significance (MGUS) serum derived EVs suggesting their involvement in MM pathogenesis or progression. To investigate the effect of circulating EVs on endothelial and myocardial cells, we purified MM and MGUS serum derived EVs with differential ultracentrifugation protocols and tested their biological activity. We found that MM and MGUS EVs induced different proliferation and internalization rates in endothelial and myocardial cells, thus we tried to find specific targets in MM EVs docking and processing. Pre-treatment of EVs with anti-FLCs antibodies or heparin blocked the MM EVs uptake, highlighting that FLCs and glycosaminoglycans are involved. Indeed, only MM EVs exposure induced a strong nuclear factor kappa B nuclear translocation that was completely abolished after anti-FLCs antibodies and heparin pre-treatment. The protein tyrosine kinase c-src is present on MM circulating EVs and redistributes to the cell plasma membrane after MM EVs exposure. The anti-FLCs antibodies and heparin pre-treatments were able to block the intracellular redistribution of the c-src kinase and the subsequent c-src kinase containing EVs production. Our results open new insights in EVs cellular biology and in MM therapeutic and diagnostic approaches.

Keywords: extracellular vesicles, serum-free light chain, glycosaminoglicans, NfkB, multiple myeloma

\section{INTRODUCTION}

Extracellular vesicles (EVs) are emerging as pleiotropic actors in intercellular signaling. The discovery of exosome (a specific subpopulation of EVs) mediated transfer of specific mRNAs and miRNAs (1) opened the door for EVs research in cancer biogenesis and progression. Indeed, EVs carry a broad number of cargos such as molecules that take part in determining cell identity, signaling pathways, and deregulation in many cancer forms.

Exosomes are the most attractive models in EVs interplay studies because they originate from specific intracellular compartments such as endosomes and multivesicular bodies. Moreover, growing evidences show that tumors constitutively shed exosomes with immunosuppressive effects regulating tumor growth, invasion, angiogenesis, and metastasis (2).

Evs involvement in multiple myeloma (MM) is starting to be unveiled too. It has been published that normal and MM bone marrow-mesenchymal stem cells (BM-MSC)-derived exosomes differentially affect MM cell homing and growth in vivo. A novel mechanism by which BM-MSCs play an oncogenic role in
MM is the epigenetic transfer of exosomal miRNA to the tumor clone (3).

Label-free relative quantitative proteomic analysis of circulating MM EVs identified an EVs specific protein content (4), while we showed that monoclonal gammopathy of undetermined significance (MGUS) derived EVs are different from those produced in MM (5). Indeed, we observed a significant increase in EVs production in MM patients, and monoclonal immunoglobulin free light chains (FLCs) were rerouted in the extracellular space via EVs. The serum vesicles from MM patients contained the "proto-oncogene" c-src kinase compared to MGUS and control subjects. It has been shown that constitutive activation of c-src promotes cell survival, proliferation, and chemoresistance in MM $(6,7)$ and our finding highlights the involvement of EVs as c-src kinase transactivating carriers (5). Specific targeting of EVs is probably related to their cellular origin and function. Cell-specific proteins represent a means by which exosomes can specifically dock various recipient cells by either interaction with cell-surface adhesion molecules or through interaction 
with cell-surface heparan sulfate proteoglycans (2). Phagocytosis is also involved in specific EVs uptake into the cell in a cell-type dependent manner (8). As potential targeting sites, heparan sulfate proteoglycans have been shown to function as internalizing receptors of cancer cell-derived EVs (9). Furthermore, glycosaminoglycans (GAGs) are involved in FLCs fibrillation and amyloidogenesis: the evidences that amyloid-related light chain proteins and GAGs, particularly heparin, interact, suggest that the therapeutic use of GAGs antagonists to prevent amyloidosis (10).

Shed syndecan-1 (CD138), a GAG binding protein, is known to actively promote myeloma tumor growth, angiogenesis, and metastasis in MM (11) and patients with high-serum levels of heparanase develop more severe illness. The mechanism of heparanase aggressive phenotype priming is in part due to synergy with the heparan sulfate proteoglycan syndecan-1 to create a niche within the bone marrow microenvironment, further driving myeloma growth and dissemination $(12,13)$. The evidences that syndecan-1 and heparanase are also involved in exosomes generation/uptake thus indicate a potential mechanism in MM EVs trafficking (14).

In the present work, we studied the biological activity of "as pure as possible" serum EVs. As pure as possible, thus, named EVs instead of exosomes, because purified serum samples may contain protein aggregates and ectosomes. At the moment, separation of ectosomes and exosomes with the same size and density is still difficult. To investigate the EVs effect on endothelial and myocardial cells we used gradient fraction grade purity EVs populations and found that MM EVs induce a significant higher proliferation rate than MGUS EVs. We also found that while MM EVs are internalized, MGUS EVs are not. Internalization was blocked with anti-FLCs antibodies or heparin pre-treatment. More strikingly, we found that MM EVs induced a c-src kinase containing EVs release and nuclear factor kappa $\mathrm{B}(\mathrm{Nf} \kappa \mathrm{B})$ nuclear translocation in cultured cells and both processes were blocked by anti-FLCs antibodies and heparin treatment.

In summary, this paper reports a novel potential use of antiFLCs antibodies in MM patients together with heparin analogs. Furthermore, we propose the EVs-NfkB translocation assay for monitoring MGUS patients.

\section{MATERIALS AND METHODS \\ ETHICS STATEMENT AND SAMPLE COLLECTION}

Serum samples were collected in the Laboratory of Clinical Biochemistry, Azienda Ospedaliera Spedali Civili of Brescia (AOSCB). After routine analysis, waste serum samples were coded, anonymized and frozen at $-80^{\circ} \mathrm{C}$ : monoclonal components were detected by high-resolution agarose gel electrophoresis/immunofixation (Interlab). Immunoglobulin FLC concentration was measured by particle enhanced nephelometry (Freelite assay, The Binding Site) on a Behring BNII Nephelometer (Dade Behring). The institutional review board of Azienda Ospedaliera Spedali Civili of Brescia approved the study in adherence with the Declaration of Helsinki (REC number: SFLC01). All traceable identifiers were removed before analysis to protect patient confidentiality and all samples were analyzed anonymously. Samples analyzed include six patients with diagnosed MM (MM1-6), three
MGUS patients (MGUS1-3), and three healthy donors used as controls (c1-3).

\section{EVs PURIFICATION AND FRACTIONATION}

To obtain heterogenous EVs populations, $1 \mathrm{ml}$ serum sample was processed with serial centrifugation steps $(800 \times g$ for $30 \mathrm{~min}$, $16,000 \times g$ for $45 \mathrm{~min}, 100,000 \times g$ for $2 \mathrm{~h}$ ) and the pellets were re-suspended in $50 \mu \mathrm{l}$ PBS $1 \times$ supplemented with 1:1000 Protease Inhibitor Cocktail (P.I., Sigma). Reducing sample buffer was added and the samples were boiled $5 \mathrm{~min}$ at $95^{\circ} \mathrm{C}$. Samples were electrophoresed in SDS-PAGE and analyzed by western blot (WB). The heterogeneous EVs populations were subsequently processed for further fractionation using a discontinuous sucrose gradient as described in the next paragraph. Samples were normalized for protein content (Bradford assay) whenever possible; in alternative, equal volumes of each sample were loaded on an acrylamide-bisacrylamide gel.

\section{SUCROSE GRADIENT}

The heterogeneous EVs populations ( $200 \mu \mathrm{g}$ of pelleted proteins) were re-suspended in $800 \mu \mathrm{l}$ buffer A (10 mM Tris- $\mathrm{HCl} 250 \mathrm{mM}$ sucrose, $\mathrm{pH} 7.4$ ), loaded at the top of a discontinuous sucrose gradient $(15,20,25,30,40,60 \%$ sucrose in $10 \mathrm{mM}$ Tris- $\mathrm{HCl}, \mathrm{pH} 7.4)$ and centrifuged at $100,000 \times g$ for $16 \mathrm{~h}$ at $4^{\circ} \mathrm{C}$ (rotor MLS 50, Beckman Optima MAX). Twelve fractions with equal volumes $(400 \mu \mathrm{l})$ were collected from the top of the gradient, and the vesicles were pelleted by ultracentrifugation $(100,000 \times g$ for $2 \mathrm{~h})$. The pellets were re-suspended in $50 \mu \mathrm{l}$ of $100 \mathrm{mM}$ Tris, $150 \mathrm{mM} \mathrm{NaCl}, 1 \mathrm{mM}$ EDTA supplemented with 1:1000 Protease Inhibitor Cocktail (P.I., Sigma). Reducing sample buffer was added and the samples were boiled $5 \mathrm{~min}$ at $95^{\circ} \mathrm{C}$. Samples were electrophoresed in SDS-PAGE and analyzed by WB. Positive fractions containing EV markers (from 6 to $9,1.11-1.22 \mathrm{~g} / \mathrm{cm}^{3}$ ) were further investigated by atomic force microscopy (AFM), scanning electron microscopy (SEM), and lipid fluorescent labeling.

\section{SCANNING ELECTRON MICROSCOPY (SEM)}

Extracellular vesicles were purified from $1 \mathrm{ml}$ serum with serial centrifugations and fractionated onto a discontinuous sucrose gradient as described before. Fractions known to be positive for EV markers were ultra-centrifuged $(100,000 \times g$ for $2 \mathrm{~h})$, pellets were re-suspended in $200 \mu \mathrm{l}$ PBS $1 \times$, and centrifuged $(400 \times g$ for $5 \mathrm{~min}$ ) with a Cytospin 4 centrifuge (The Thermo Scientific). Samples were fixed with $2.5 \%$ glutaraldehyde (Sigma) in PBS $1 \times$ for $1 \mathrm{~h}$. After washing twice with PBS $1 \times$, the fixed samples were dehydrated with an ascending sequence of ethanol $(25,50,75,90$, $100 \%)$. Ethanol was then washed away with high-pressure liquid carbon dioxide (critical point dryer $\mathrm{CO}_{2}$, Balzers Union). Samples were analyzed by SEM after gold sputtering (Balzers Union Sputtering System SCD 040), using a Philips 501 SEM operating at $15 \mathrm{kV}$.

\section{ATOMIC FORCE MICROSCOPY (AFM)}

Extracellular vesicles were re-suspended in $50 \mu \mathrm{l}$ of $100 \mathrm{mM}$ Tris, $150 \mathrm{mM} \mathrm{NaCl}, 1 \mathrm{mM}$ EDTA, and diluted 1:10 with deionized water. Five to $10 \mu \mathrm{l}$ of samples were then spotted onto freshly cleaved mica sheets (Grade V-1, thickness $0.15 \mathrm{~mm}$, size $15 \mathrm{~mm} \times 15 \mathrm{~mm}$ ). 
All mica substrates were dried at room temperature and analyzed using a JEOL JSPM-5200, using a Veeco AFM tip or a MikroMasch AFM tip. Images were snapped in tapping mode, scan size ranged from 0.3 to $15 \mu \mathrm{m}$ and scan speed ranged from 0.6 to $3.3 \mathrm{~ms} \times$ clock.

\section{FLUORESCENT LABELING}

Extracellular vesicles were re-suspended in Diluent C (PKH67 Green Fluorescent cell linker, Sigma) to a $70 \mu \mathrm{l}$ final volume. $1.7 \mu \mathrm{l}$ of PKH67 green fluorescent dye was added to each sample and incubated at room temperature for $10 \mathrm{~min}$. In alternative, we labeled EVs with $\mathrm{PKH} 26$ red fluorescent dye. The reaction was stopped adding $70 \mu \mathrm{l}$ of $1 \%$ BSA in PBS $1 \times$. EVs were centrifuged at $100,000 \times g$ for $2 \mathrm{~h}$.

\section{FLOW CYTOMETRY \\ EVs analysis}

Forty microliters of Exo-Flow FACS Magnetic beads $[9.1 \mu \mathrm{m}$, $400 \mu \mathrm{l}$ at $10 \mathrm{mg} / \mathrm{ml}, 1.6 \times 10^{7}$ beads/ml (SBI, System Bioscience)] were coupled with $10 \mu \mathrm{l}$ of anti-CD63 biotinylated antibody following manufacturer instructions. Afterwards, $100 \mu \mathrm{g}$ (protein concentration) of EVs were incubated on a rotating rack at $4^{\circ} \mathrm{C}$ overnight for CD63 positive EVs capture. Exosomes-coated beads were stained on ice for $2 \mathrm{~h}$ with PKH26 (Sigma, $1 \mu \mathrm{l} / 80 \mu \mathrm{g}$ of EVs proteins) and with $10 \mu \mathrm{l}$ of Exo-FITC exosome stain (SBI, System Bio-Science) and then analyzed on a FACSCanto II flow cytometer (BD Biosciences) using the FACSDiva software 2.56 (BD Biosciences).

\section{Re-suspended cells analysis}

Human vein endothelial cells (HVEC) were incubated with PKH67-labeled EVs for $4 \mathrm{~h}$ at $37^{\circ} \mathrm{C}$; subsequently, cell monolayers were washed with PBS $1 \times$, detached using trypsin, and re-suspended in PBS $1 \times$. Flow-cytometry analysis was performed on a FACSCanto II (BD Biosciences) using the FACSDiva software 2.56 (BD Biosciences). Gate was set on living cells based on forward/side scatter properties and a minimum of $10^{3}$ events within the gated live population were collected per sample. The intracellular PKH67-labeled EVs were measured by the peak fluorescence intensity shift of PKH67, calculated by the geometric mean of the population. HVECs were stained with mouse anti CD31-APC (allophycocyanin) primary antibody. Internalized EVs were stained with or without PKH67-labeled EVs (unlabeled EVs were used as cell auto-fluorescence control).

\section{EVs ACETYLCHOLINESTERASE ACTIVITY EVALUATION}

Extracellular vesicles acetylcholinesterase activity was assayed following a previously described procedure $(15,16)$. Briefly, EVs pellets from $1 \mathrm{ml}$ serum were re-suspended in $100 \mu \mathrm{l}$ of PBS $1 \times$ and incubated with $1.25 \mathrm{mM}$ acetylthiocholine and $0.1 \mathrm{mM} \mathrm{5,5-}$ dithiobis (2-nitrobenzoic acid) in a final volume of $400 \mu \mathrm{l}$. The incubation was carried out in cuvettes at $37^{\circ} \mathrm{C}$ and the absorbance change was monitored every $5 \mathrm{~min}$ at $412 \mathrm{~nm}(0-30 \mathrm{~min})$. The data represent the enzymatic activity after $20 \mathrm{~min}$.

\section{PROTEIN/LIPID RATIO CALCULATION}

Extracellular vesicles protein concentration from controls (three patients), MGUS (three patients), and MM (six patients) serum was quantified with Bradford assay. Samples were normalized for protein content $(200 \mu \mathrm{g})$. EVs were PKH67-labeled as described and re-suspended in $20 \mu \mathrm{l}$ of loading dye [ $36 \%$ Tris-acetate-EDTA (TAE), $14 \% \mathrm{H}_{2} \mathrm{O}, 50 \%$ glycerol]. Ten microliters of fluorescent EVs were spotted on a nitrocellulose membrane and dots fluorescent signal were acquired using a G:Box Chemi XT Imaging system (Syngene). Signals were quantified with the Gene Tools program. Protein content/lipid fluorescent signal ratio was calculated.

\section{CELL CULTURE}

H9C2 (ATCC CRL-1446; tissue: heart/myocardium; cell type: myoblast) cells were grown in Dulbecco's modified eagle's medium (DMEM) supplemented with $10 \%$ fetal bovine serum (FBS) (Lonza), 1\% penicillin/streptomycin (Lonza), 1\% glutamine (Lonza); HVECs (17) were grown in RPMI 1640 supplemented as DMEM, at $37^{\circ} \mathrm{C}, 5 \% \mathrm{CO}_{2}$.

\section{FRACTIONATION OF CYTOPLASMIC, MEMBRANOUS, AND NUCLEAR COMPONENTS}

HVEC monolayer were washed two times with cold PBS $1 \times$, scraped with PBS-0.1 mM EDTA, and ultra-centrifuged at $800 \times g$ for $10 \mathrm{~min}$ at $4^{\circ} \mathrm{C}$. The pellet was re-suspended in harvest buffer (10 mM Hepes pH 7.9, $50 \mathrm{mM} \mathrm{NaCl}, 0.1 \mathrm{mM}$ EDTA, 0.5\% Triton X-100, and freshly added $1 \mathrm{mM}$ DTT, $10 \mathrm{mM}$ tetrasodium pyrophosphate, $10 \mathrm{mM} \mathrm{NaF}$ ), incubated on ice for $5 \mathrm{~min}$, and centrifuged at $800 \times g$ for $10 \mathrm{~min}$ at $4^{\circ} \mathrm{C}$. The supernatant contains cytosolic and membranous proteins while the pellet, containing nuclei, was washed with Buffer A (10 mM HEPES pH 7.9, $10 \mathrm{mM} \mathrm{KCl}, 0.1 \mathrm{mM}$ EDTA, $0.1 \mathrm{mM}$ EGTA, and freshly added $1 \mathrm{mM}$ DTT, $1 \mathrm{mM}$ PMSF, $4 \mu \mathrm{g} / \mathrm{ml}$ aprotinin, $2 \mu \mathrm{g} / \mathrm{ml}$ pepstatin) and centrifuged at $800 \times g$ for $10 \mathrm{~min}$ at $4^{\circ} \mathrm{C}$. After centrifugation, the pellet was re-suspended in buffer C $(10 \mathrm{mM}$ HEPES $\mathrm{pH}$ 7.9, $500 \mathrm{mM} \mathrm{NaCl}, 0.1 \mathrm{mM}$ EDTA, 0.1 mM EGTA, 0.1\% NP-40, and freshly added $1 \mathrm{mM}$ DTT, $1 \mathrm{mM}$ PMSF, $4 \mu \mathrm{g} / \mathrm{ml}$ aprotinin, $2 \mu \mathrm{g} / \mathrm{ml}$ pepstatin) and vortexed $15 \mathrm{~min}$ at $4^{\circ} \mathrm{C}$. Finally, samples were centrifuged at $20,000 \times \mathrm{g}$ for $20 \mathrm{~min}$ at $4^{\circ} \mathrm{C}$ and the supernatant transferred in a new tube. This final fraction contains the nuclear extract.

\section{IMMUNOFLUORESCENCE}

HVEC were grown on $35 \mathrm{~mm}$ glass coverslips until $60-80 \%$ confluency and incubated at $37^{\circ} \mathrm{C}$ with equal amount of serum EVs [healthy patient (c), MGUS, and MM EVs] or only with starvation medium for $4 \mathrm{~h}$.

\section{Cellular staining}

Cells were washed with PBS $1 \times$, fixed with $3 \%$ paraformaldehyde for $15 \mathrm{~min}$, washed with $\mathrm{NH}_{4} \mathrm{Cl}$ for $15 \mathrm{~min}$, and permeabilized with $0.3 \%$ saponin in PBS three times for $10 \mathrm{~min}$. Primary antibodies were incubated for $1 \mathrm{~h}$ and washed three times for $10 \mathrm{~min}$ with $0.3 \%$ saponin in PBS $1 \times$. Secondary antibodies were incubated for $45 \mathrm{~min}$ and washed as described above. Coverslips were mounted using an anti-fade mounting medium (ProLongGoldInvitrogen) on a glass slide. Fluorescent microscopy was performed on a ZEISS Axiovert 100 microscope using the $63 \times$ Zeiss oil immersion objective. Images were processed with the use of Image pro-plus 4.5.1. 


\section{Nuclear staining}

Cells were washed with PBS $1 \times$, fixed with $4 \%$ paraformaldehyde for $10 \mathrm{~min}$, permeabilized with $0.2 \%$ Triton X-100, $2 \mathrm{mg} / \mathrm{ml}$ BSA, $1 \mathrm{mM} \mathrm{NaN}_{3}$ in PBS on ice three times for $10 \mathrm{~min}$. Then cells were incubated with blocking solution $(0.02 \%$ Triton $\mathrm{X}-100$, $3 \%$ BSA, $1 \mathrm{mM} \mathrm{NaN}_{3}$ in PBS). Primary antibodies were incubated for $30 \mathrm{~min}$ in blocking solution and washed three times for 10 min with wash buffer (PBS, $0.02 \%$ Triton X-100, 1.5\% BSA, $1 \mathrm{mM} \mathrm{NaN}_{3}$ ). Secondary antibodies were incubated for $45 \mathrm{~min}$ and washed as described above.

\section{EVs UPTAKE}

To evaluate cells internalization rate of MGUS and MM EVs, HVEC, and H9C2 (40,000 cell/dish of $35 \mathrm{~mm}$ ) cells were incubated $4 \mathrm{~h}$ with PKH67 (Green Fluorescent Cell Linker Kit-Sigma) labeled EVs $\left(200 \mu \mathrm{g}\right.$ of proteins) at $37^{\circ} \mathrm{C}$. As negative controls cells were incubated with PKH67 centrifuged $2 \mathrm{~h}$ at $100,000 \times g$ without EVs to exclude the presence of PKH67 aggregates. Furthermore, to block endocytosis cells were pre-incubated for $30 \mathrm{~min}$ at $4^{\circ} \mathrm{C}$ or with nocodazole $20 \mu \mathrm{M}$ (Sigma) at $37^{\circ} \mathrm{C}$. After these pre-incubations, PKH67-labeled EVs $(200 \mu \mathrm{g})$ were added and incubated $4 \mathrm{~h}$, respectively, at $4^{\circ} \mathrm{C}$ or in the presence of the drug (18). Intracellular uptake was tested by immunofluorescence.

To investigate the EVs uptake mediators, before cell treatment, EVs were incubated with $10 \mu \mathrm{g}$ of Abs (sheep anti-FLCs or mouse anti-CD63) for $2 \mathrm{~h}$ at $4^{\circ} \mathrm{C}$ and afterwards EVs were ultracentrifuged to separate unbound Abs. In alternative, serum EVs were pre-treated or not with heparin (Sigma) at a final concentration of $100 \mathrm{ng} / \mathrm{ml}$ for $30 \mathrm{~min}$ at $4^{\circ} \mathrm{C}$. Intracellular uptake was tested by immunofluorescence and/or flow-cytometry.

\section{PROLIFERATION ASSAY}

Eight thousand cells/well (12 multi-well plate) were cultured in RPMI serum-free and control $(n=3), \operatorname{MGUS}(n=3), \operatorname{MM}(n=6)$ derived EVs $(50 \mu \mathrm{g}$ proteins) were added for 24,48 , and $72 \mathrm{~h}$, respectively. Cell proliferation rates were assessed using crystal violet absorbance. The absorbance values were measured at $540 \mathrm{~nm}$.
We calculated the growth factor index with the "doubling time online calculator." The cell doubling time index determines the dynamics of the cell culture development as average time taken for a cell to complete the cell cycle within several days $(24,48$, $72 \mathrm{~h}$ ). Average of three independent experiments is shown. $T$-test $p$-values were also calculated.

\section{ANTIBODIES AND IMMUNOBLOTTING}

The following antibodies were used in our experiments: mouse anti-Hsp 70 (Enzo Life Science), rabbit anti-NfкB (Santa Cruz), rabbit anti c-src (Santa Cruz), mouse anti-CD63 (Millipore), mouse anti-Tsg 101 (Abcam), mouse anti- $\alpha$-tubulin (Millipore: Mab1637), mouse anti-Annexin V (Santa Cruz), mouse antiLamin A/C (Novus), sheep anti- $\lambda$ FLC and sheep anti-k FLC antibodies (Bethyl Laboratories, USA and the Binding Site, UK), and goat anti-Histone H3 (Santa Cruz).

Extracellular vesicles from patients' serum were obtained as described before. The supernatants were normalized for protein concentration (Bradford Assay) when possible (in alternative equal volumes of each sample were loaded on a acrylamidebisacrylamide gel), boiled in reducing SDS sample buffer $(80 \mathrm{mM}$ Tris, pH 6.8, 2\% SDS, 7.5\% glycerol, $0.01 \%$ bromophenol blue) supplemented with 2\% 2-mercaptoethanol (Sigma) for $5 \mathrm{~min}$ at $95^{\circ} \mathrm{C}$ and separated by SDS-PAGE on a acrylamide/bisacrylamide (10 or $12.5 \%)$ gel and analyzed by WB.

To visualize the FLC signal, we performed electrophoresis under native conditions: samples were re-suspended in nonreducing sample buffer (50 mM Tris, 2\% SDS, 10\% glycerol, $0.01 \%$ bromophenol blue $\mathrm{pH} 6.8$ ) and boiled for $5 \mathrm{~min}$ at $95^{\circ} \mathrm{C}$.

Afterwards, samples were run in a $12.5 \%$ acrylamidebisacrylamide SDS $0.4 \%$ gel, transferred for $1 \mathrm{~h}$ onto a PVDF membrane and blocked overnight with 5\% fat-free milk, $0.05 \%$ Tween-20 in PBS. The PVDF membrane was incubated with the antibodies described above for $2 \mathrm{~h}$ in PBS Tween $0.05+1 \%$ fat-free milk. The membranes were washed $3 \times$ for 10 min with PBS Tween $0.05 \%$ and incubated for $1 \mathrm{~h}$ with one of the following secondary antibodies: rabbit anti-mouse and goat anti-rabbit (Zymed), rabbit anti goat, and donkey anti-sheep (Jackson Immuno Research).

Table 1 | Description of the patients involved in the study.

\begin{tabular}{|c|c|c|c|c|c|c|c|c|c|c|}
\hline Patients & Disease & k FLC (mg/I) & $\lambda \mathrm{FLC}(\mathrm{mg} / \mathrm{I})$ & Ratio & S-IF & U-IF & $\lg A$ mg/dl & lgG mg/dl & $\lg M$ mg/dl & Creatinine $(\mathrm{mg} / \mathrm{dl})$ \\
\hline c 1 & Healthy & 18.4 & 13.5 & 1.36 & neg. & neg. & 159 & 1560 & 137 & 0.65 \\
\hline c 2 & Healthy & 20.1 & 8.9 & 2.26 & neg. & neg. & 96 & 1130 & 129 & 0.51 \\
\hline c 3 & Healthy & 7.4 & 17.5 & 0.42 & neg. & neg. & 298 & 1120 & 122 & 0.49 \\
\hline MGUS 1 & MGUS & 1.69 & 608 & 0.00 & $\lg G / \lambda$ & $\lambda$ & 20.1 & 2010 & 28.7 & 0.6 \\
\hline MGUS 2 & MGUS & 9.36 & 284 & 0.03 & $\lg G / \lambda$ & neg. & 28.7 & 2220 & 15.2 & 0.9 \\
\hline MGUS 3 & MGUS & 12.9 & 105 & 0.12 & $\lambda$ & neg. & 809 & 845 & 66.4 & 0.64 \\
\hline MM 1 & Multiple myeloma & 1210 & 22 & 55.00 & $\lg G / k$ & k & 85.3 & 729 & 22.4 & 0.85 \\
\hline MM 2 & Multiple myeloma & 1550 & 4.85 & 319.59 & $\lg G / k$ & k & 26 & 978 & 23.4 & 2 \\
\hline MM 3 & Multiple myeloma & 1360 & 6.15 & 221.14 & $\lg G / k$ & k & 46.1 & 519 & 17.7 & 0.8 \\
\hline MM 4 & Multiple myeloma & 26.6 & 864 & 0.03 & $\lambda$ & $\lambda$ & 22.6 & 581 & 23.7 & 1.5 \\
\hline MM 5 & Multiple myeloma & 73.9 & 1130 & 0.07 & $\lambda$ & $\lambda$ & 174 & 1150 & 142 & 2.6 \\
\hline MM 6 & Multiple myeloma & 2.45 & 4450 & 0.00 & $\lambda$ & $\lambda$ & 204 & 727 & 22.8 & 0.9 \\
\hline
\end{tabular}

S-IF, serum immunofixation; U-IF, urine immunofixation; neg., negative. 
A

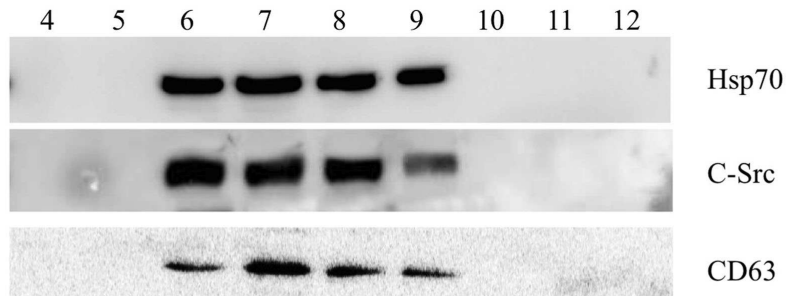

M1k EVs

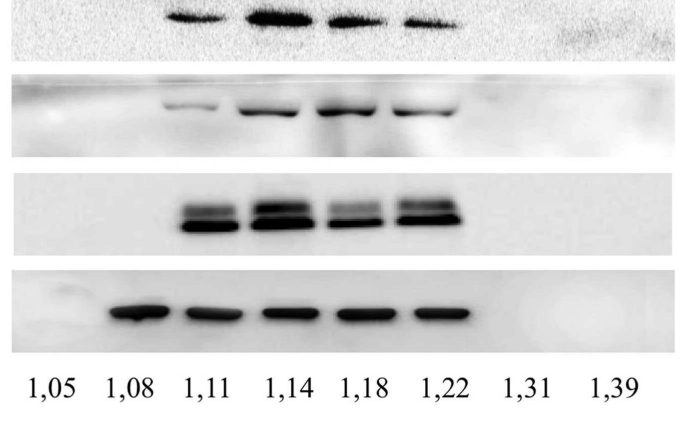

CD63

Tsg101

Annexin V

K FLCs

Density

$\mathrm{g} / \mathrm{cm}^{3}$

B 1 Antibody coated beads

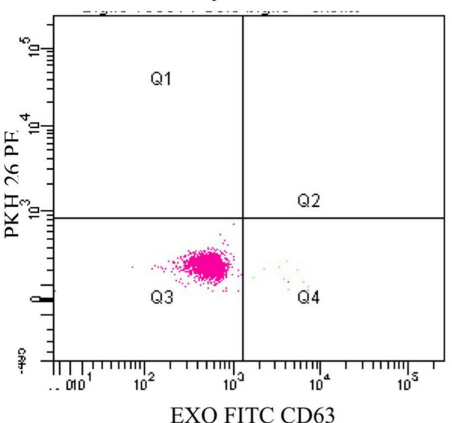

2

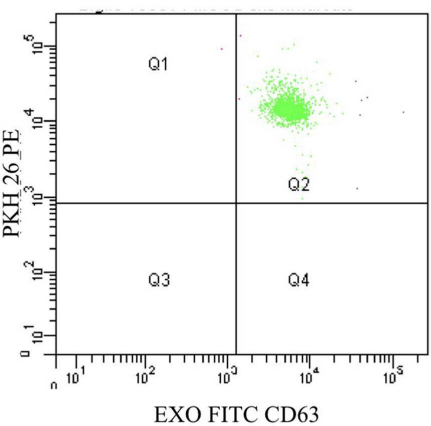

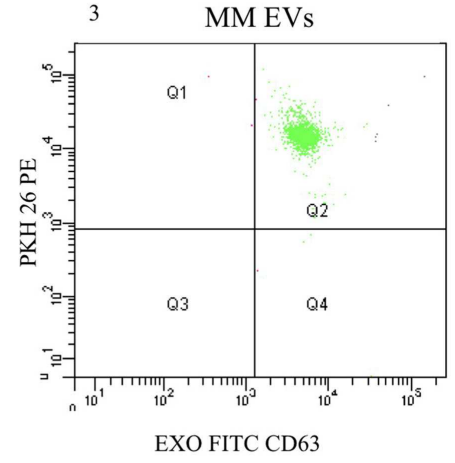

C

SEM
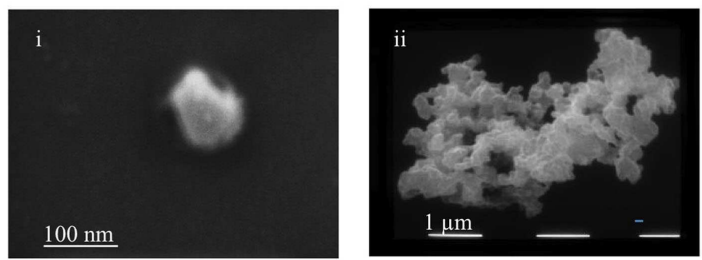

D
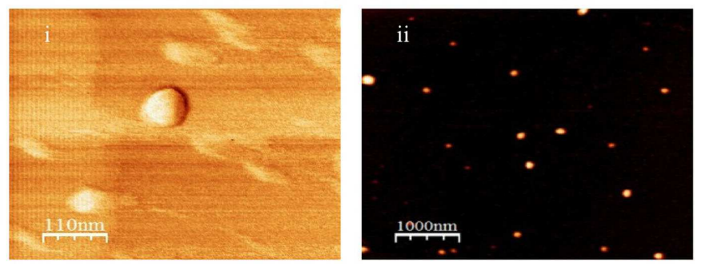

FIGURE 1 | Serum EVs characterization. (A) Ultra-centrifuged EVs were loaded on the top of a $15-60 \%$ discontinuous sucrose gradient. Twelve fractions of equal volume were collected from the top (low density, fraction 1) to the bottom (high density, fraction 12). Samples were electrophoresed and analyzed by WB using anti-HSP70, anti-c-src, anti-CD63, anti-Tsg101, anti-Annexin V, and anti-FLCs antibodies. The EVs probed markers were identified in fractions 6-9 corresponding to the buoyant density of $1.11-1.22 \mathrm{~g} / \mathrm{cm}^{3}$. (B) EVs were purified with
CD63 Exo-Flow FACS magnetic beads. CD63 coated EVs were then incubated with PKH26. The data show PKH26 (PE) versus CD63 (FITC) intensity. The first panel (1) depicts antibody coated beads, the second (2) MGUS EVs, and the third (3) MM EVs. (C) Scanning electron microscopy (SEM) imaging of the serum EVs: (i) $80,000 \times$, scale bar $100 \mathrm{~nm}$; (ii) 20,000x, scale bar $1 \mu \mathrm{m}$. (D) Atomic force microscopy (AFM) image of serum EVs: (i) phase, scale bar $110 \mathrm{~nm}$ and (ii) topography, scale bar $1 \mu \mathrm{m}$. 
A

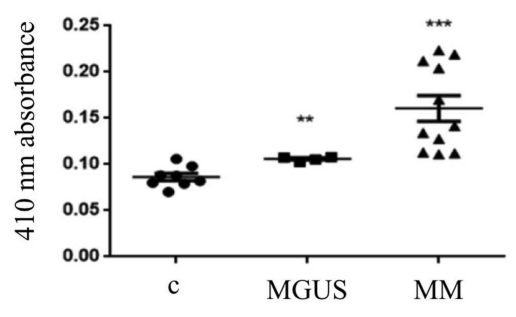

C

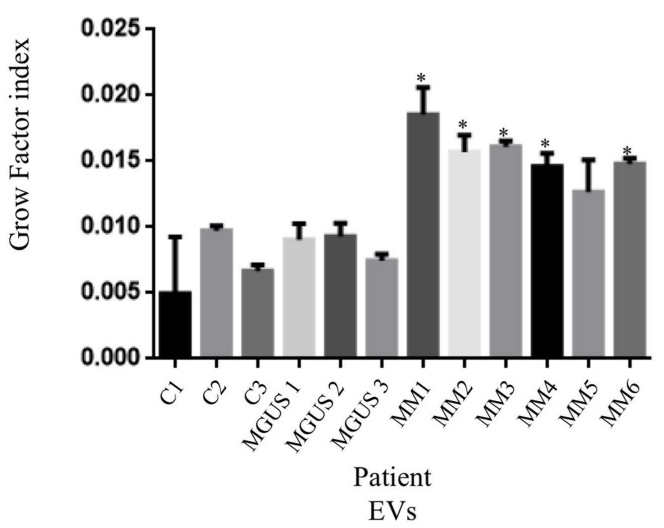

D

HVEC

$37^{\circ} \mathrm{C}$

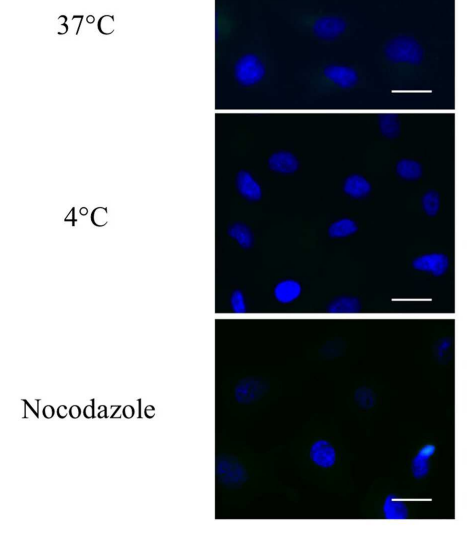

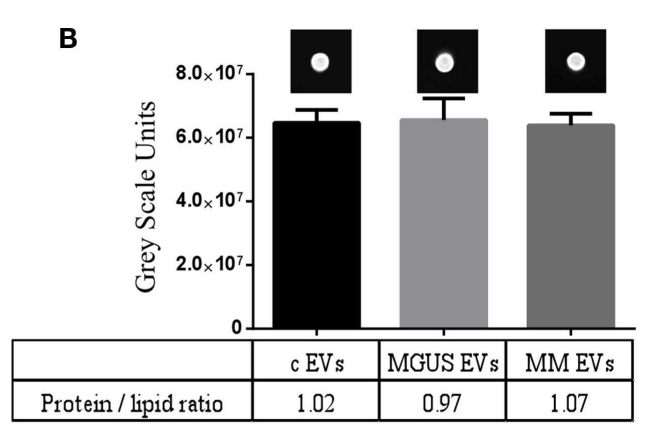

H9C2 Proliferation

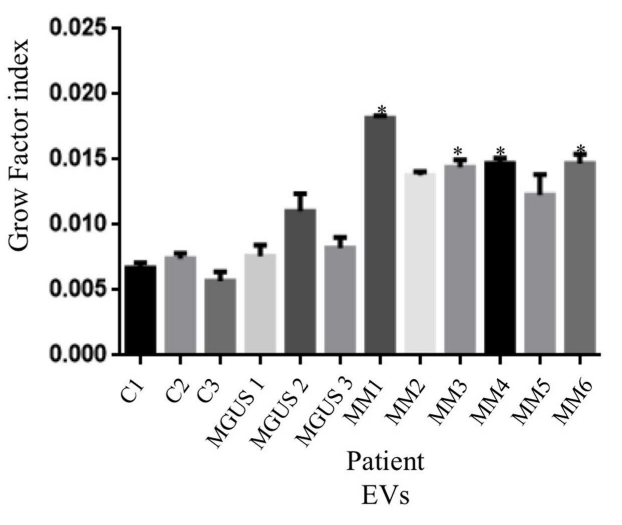

E

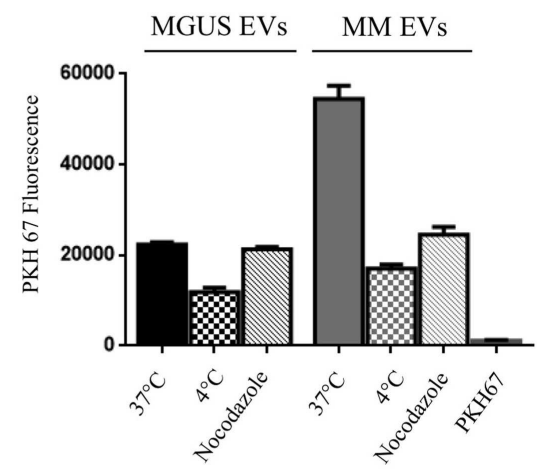

PKH67

FIGURE 2 | Internalized MM EVs increase HVEC and H9C2 proliferation. (A) Evaluation of the acetylcholinesterase activity in $50 \mu \mathrm{g}$ of controls (c, 8 different patients), MGUS (4 patients), and MM (10 patients) crude EVs samples. Significant differences were determined with Student's $t$-test: ${ }^{*} p<0.05,{ }^{* *} p<0.01,{ }^{* * *} p<0.001$. Values were shown as mean SEM of at least three experiments. (B) Fluorescent (PKH67-labeled) EVs (200 $\mu \mathrm{g}$ of proteins) from controls, MGUS, and MM patients were re-suspended with loading buffer [36\% TAE (Tris-acetate-EDTA), $14 \% \mathrm{H}_{2} \mathrm{O}, 50 \%$ glycerol] to a final volume of $20 \mu \mathrm{l}$. Ten microliters were spotted on a nitrocellulose membrane and dots fluorescent signal were acquired using a G:Box Chemi XT Imaging system (Syngene). Signals were quantified with the program Gene Tools. Protein/lipid ratio was quantified for all samples. Mean values \pm SEM of at least four different experiments. (C) HVEC and H9C2 cells in serum-free medium were incubated with $50 \mu \mathrm{g}$ of controls (c1-3, 3 different patient), MGUS (1-3), and MM (MM 1-6) EVs for 24, 48, and $72 \mathrm{~h}$ and cell proliferation rate (growth factor) was assessed using crystal violet. Mean values \pm SEM for three independent experiments are shown.

(Continued) 


\section{FIGURE 2 | Continued}

${ }^{*} p<0.05,{ }^{*} p<0.01,{ }^{* *} p<0.001$ (D) HVECs were incubated with PKH67-labeled MGUS and MM EVs (200 $\mu \mathrm{g}$ of proteins) for $4 \mathrm{~h}$ at $37^{\circ} \mathrm{C}$; as negative controls cells were pre-incubated for $30 \mathrm{~min}$ at $4^{\circ} \mathrm{C}$ or with nocodazole $20 \mu \mathrm{M}$ at $37^{\circ} \mathrm{C}$ followed by $4 \mathrm{~h}$ of exposure to $\mathrm{EVs}$ at $4^{\circ} \mathrm{C}$ or in the presence of nocodazole. Cells were then washed with PBS $1 \times$ and fixed with $3 \%$ PFA, permeabilized with $0.3 \%$ saponin, and stained with DAPI. Scale bar $5 \mu \mathrm{m}$. Coverslips were mounted using an anti-fade mounting medium (ProLong Gold-Invitrogen) on a glass slide. Fluorescent microscopy was performed on a ZEISS Axiovert 100 fluorescent microscope using the $63 x$ Zeiss oil immersion objective. Single sections are shown for each condition. Images were processed with the use of Image pro-plus 4.5.1. (E) PKH67 fluorescence intensity measurement of internalized MGUS and MM EVs before and after endocytosis blockage at $4^{\circ} \mathrm{C}$, with nocodazole $20 \mu \mathrm{M}$. Internalization rate of PKH67 centrifuged $2 \mathrm{~h}$ at $100,000 \times g$ without EVs. $(100$ Cells each experimental point). Images were processed with the use of Image pro-plus 4.5.1. Mean value and SEM of three independent duplicate experiments are given
Blots were detected using Luminata Classic HRP western substrate (Millipore). Images were acquired using a G:Box Chemi XT Imaging system (Syngene, UK). For densitometric analysis, we took advantage of the Gene Tools (Syngene, UK) software to compare the protein quantification of monoclonal bands.

\section{STATISTICAL ANALYSIS}

Significant differences among MGUS datasets and other samples [healthy patient (c) and MM] were determined with Student's $t$ test (Graph Pad). $p$-Values of $<0.05$ were considered statistically significant with ${ }^{\star} p<0.05,{ }^{* *} p<0.01$, and ${ }^{* *} p<0.001$. Values were shown as mean \pm SEM (Standard error of the mean) of at least three experiments.

Significant differences among different treatments on EVs or cells were determined with Student's $t$-test (Graph Pad). ${ }^{\star} p<0.05$, ${ }^{\star *} p<0.01$, and ${ }^{\star * *} p<0.001$.

\section{RESULTS}

\section{MGUS AND MM SERUM EVs CHARACTERIZATION}

We purified serum EVs populations from three control subjects (c1-3), three MGUS subjects (MGUS 1-3), and six MM patients (MM 1-6) (Table 1). We decided to use serum instead of plasma for a first line purification because serum does not contain high amounts of coagulation factors that could bind and aggregate EVs. It is well known that EVs from human blood are of high interest because of diagnostic and therapeutic purposes. Commercially available kits that allow "easy isolation procedures" are increasingly developed. Such approaches should be taken cautiously because they often fail to distinguish between differently sized EVs and membrane-free macromolecular aggregates (19). We used a step gradient protocol without filters and characterized the isolated material with AFM, SEM, and flow-cytometry. As shown in Figure 1A, we obtained four gradient fractions (from six to nine) containing some typical exosomal markers and pooled them for subsequent assays and analysis. FACS analysis was performed on PKH26 and CD63 (FITC) labeled EVs and coated with Exo-Flow FACS magnetic beads. MGUS and MM patients presented the same profile in the CD63 expression level (Figure 1B). To better characterize the composition of serum EVs, we performed morphological analyses using SEM. Figure 1C shows the presence of vesicles with diameters from 60 to $100 \mathrm{~nm}$ in MM serum samples. The pelleted serum derived vesicles were observed as single vesicles (Figure 1Ci) or vesicles clusters (Figure 1Cii) as previously described for exosomes isolated from different biological fluids (20). More clearly, the punctate pattern in AFM, which was performed on native vesicles, indicates that the EVs were pure and free of aggregates contaminants (Figures 1Di,ii).

\section{SERUM DERIVED MM AND MGUS EVS INDUCE DIFFERENT ENDOTHELIAL AND MYOCARDIAL PROLIFERATION AND INTERNALIZATION RATES}

In order to verify the amount of EVs in control (c), MGUS, and MM patients, we evaluated the acetylcholinesterase activity in EVs purified from $1 \mathrm{ml}$ of serum after serial centrifugation steps (Figure 2A). MM patients showed the highest enzymatic activity indicating a higher EVs amount than MGUS and c. We decided to normalize the EVs protein concentration on lipid content to load the same EVs amount on cells. EVs from $1 \mathrm{ml}$ serum from control (three patients), MGUS (three patients), and MM (six patients) were pelleted after serial centrifugation steps. EVs protein concentration was determined. Samples were normalized for their protein content $(200 \mu \mathrm{g})$ of pelletted proteins, EVs lipids were labeled with PKH67 and spotted on a nitrocellulose membrane (Figure 2B). Dot fluorescence intensity was acquired using a G:Box Chemi XT Imaging system (Syngene) and signals were quantified with the Gene Tools program. Samples protein content was normalized on the lipid fluorescent signal and ratios were almost identical for the different EVs preparations (protein/lipid ratio controls 1.02, MGUS 0.97, MM 1.07, Figure 2B). Consequently, $50 \mu \mathrm{g}$ of EVs obtained from control, MGUS, and MM patients were incubated 24,48 , and $72 \mathrm{~h}$ respectively, at $37^{\circ} \mathrm{C}$, on endothelial and myocardial monolayers. Cell proliferation rates were assessed using crystal violet absorbance. The growth factor index was calculated with the "doubling time online calculator" and represented as scale bars (Figure 2C). Statistical analysis showed a significant difference between cell monolayers incubated in the presence of different EVs. Particularly, MM EVs clearly enhanced the proliferation rates. These data are of interest for further investigation on patients with amyloidosis because heart failure is the major negative prognostic factor in such patients (21).

To investigate if the EVs inducible proliferation is uptake dependent, we incubated endothelial monolayers with PKH67 labeled EVs $(200 \mu \mathrm{g})$ for $4 \mathrm{~h}$ at $37^{\circ} \mathrm{C}$. Images of washed and fixed cells clearly show that only few amounts of MGUS EVs were internalized in endothelial cells whereas active MM EVs uptake is evident (Figures 2D,E). This effect is endocytosis-mediated, MM EVs show an uptake decrease of 69 and 53\%, respectively, when cells are incubated at $4^{\circ} \mathrm{C}$ or with the endocytosis inhibitor nocodazole. We also tested EVs uptake specificity, incubating cells with PKH67 without EVs and, in this condition, the fluorescent label is not internalized (Figure 2E). Same experiments were performed with H9C2 cells and gave similar results (data not shown).

\section{FLCs AND GAGs MEDIATE MM EVs INTRACELLULAR UPTAKE}

The long-distance action of EVs is probably related to specific docking signals in recipient cells. Autocrine models have also 


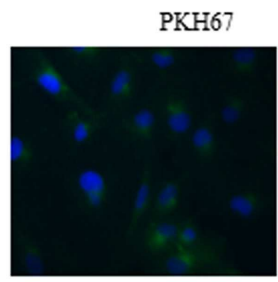

MM

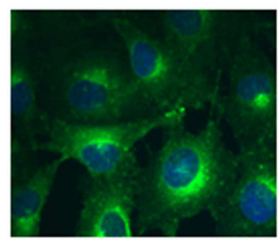

MM

$+$

shanti

FLCs

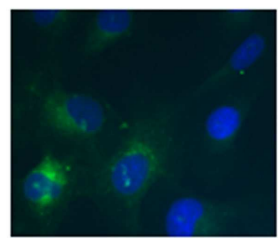

MM

$+$

heparin
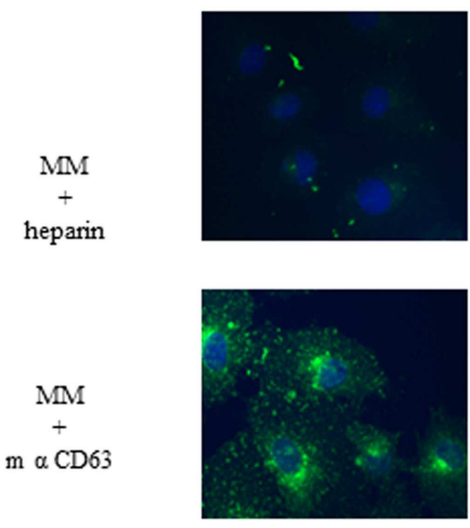

C

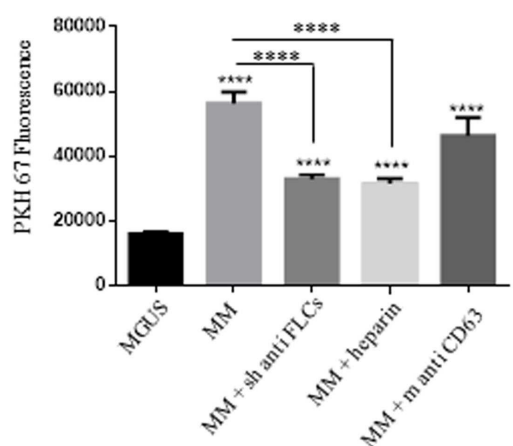

FIGURE 3 | Free light chains and GAGs mediate MM EVs intracellular uptake. (A) Fluorescent microscopy analysis of HVECs incubated with MGUS and MM PKH67-labeled EVs (200 $\mu \mathrm{g}$ of proteins) for $4 \mathrm{~h}$ at $37^{\circ} \mathrm{C}$. Before cell treatment, MM EVs were incubated with sheep anti-FLCs ( $M M+$ sh anti FLC), mouse anti-CD63 (MM + sh anti-CD63) antibody or with heparin $100 \mathrm{ng} / \mathrm{ml}$ (MM + heparin). (B) Quantitative data from similar experiments analyzed by flow cytometry. HVECs were labeled with CD31-APC (endothelial marker) and EVs were labeled with PKH67-FITC. (C) PKH67 fluorescence intensity measurement of internalized MM EVs incubated with sheep anti-FLCs,
B

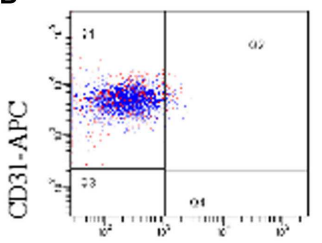

PKH67- FITC

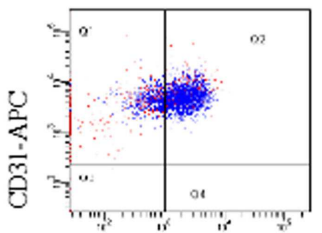

PKH67- FITC

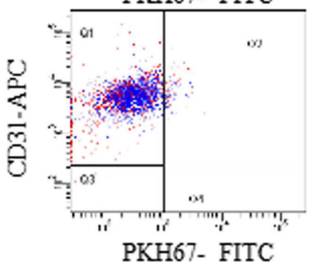

PKH67- FITC
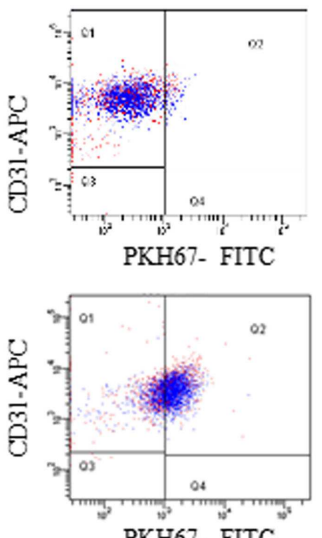

PKH67- FITC

D

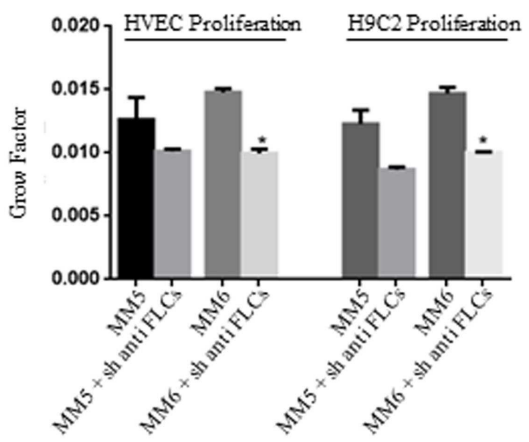

mouse anti-CD63 antibody or with heparin $100 \mathrm{ng} / \mathrm{ml}$ (MM + heparin) (100 cells each experimental point) using ImageJ program. Significant differences were determined with Student's t-test. Values were shown as mean values \pm SEM of at least three experiments. ${ }^{*} p<0.05,{ }^{*} p<0.01$, ${ }^{* *} p<0.001$. (D) HVEC and H9C2 cells in serum-free medium were incubated for 24,48 , and $72 \mathrm{~h}$ with $50 \mu \mathrm{g}$ of MM 5 and MM 6 EVs pre-treated or not with a polyclonal anti-FLCs antibody. Cell proliferation rate (growth factor) was assessed using crystal violet. Mean values \pm SEM for three independent experiments are shown. ${ }^{*} p<0.05,{ }^{*} p<0.01,{ }^{* *} p<0.001$. 
A

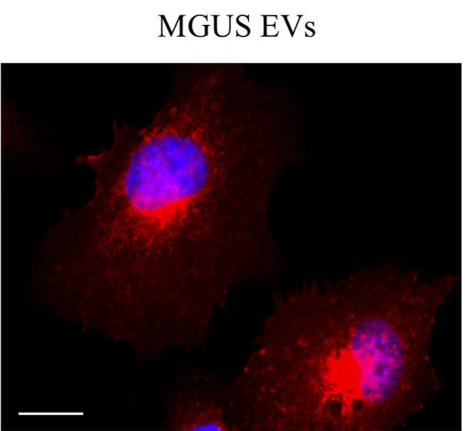

MGUS Evs

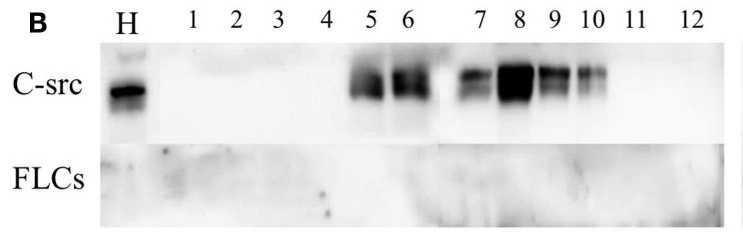

MM EVs

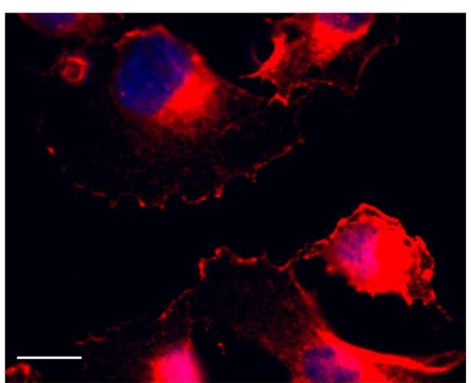

MM Evs

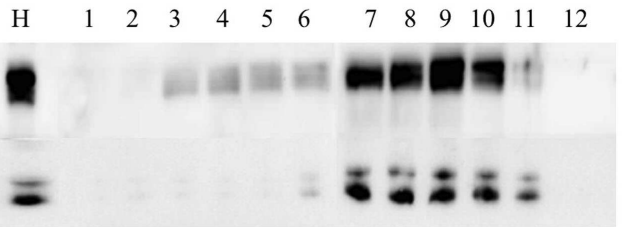

C

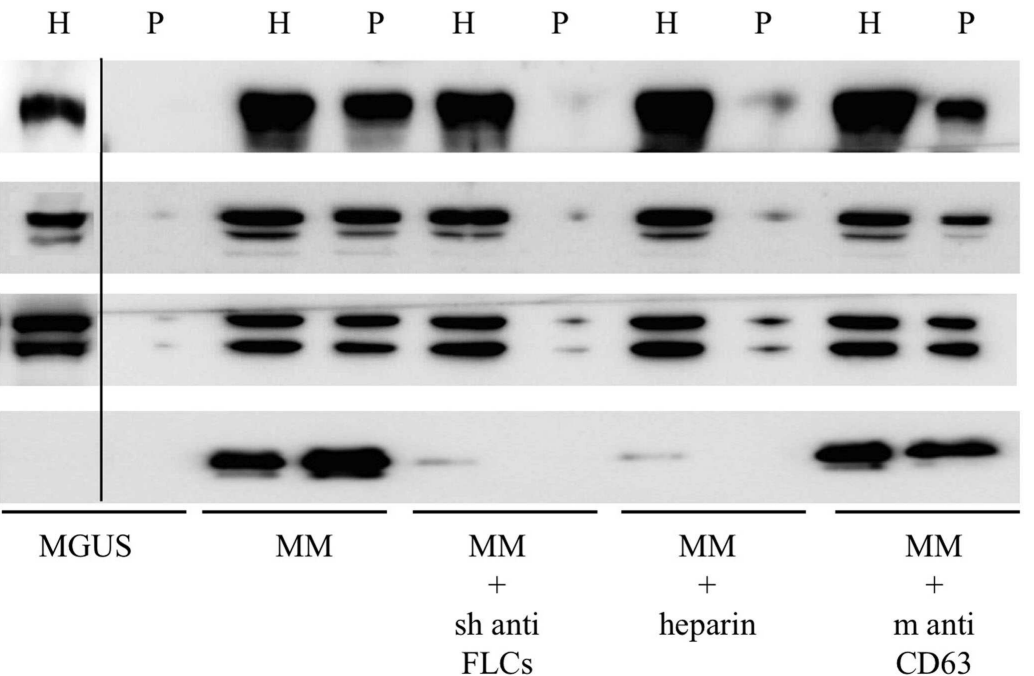

D

C-src quantification in secreted EVs

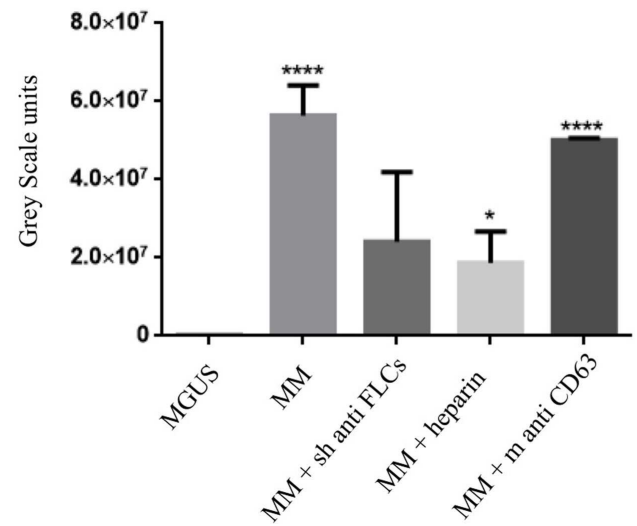

Lamp 1

C-Src

Annexin V

K FLCs 


\section{FIGURE 4 | Continued}

(A) HVECs were incubated with $200 \mu \mathrm{g}$ of MGUS and MM serum EVs for $4 \mathrm{~h}$ at $37^{\circ} \mathrm{C}$. Cells were washed with PBS $1 \times$ and fixed with $3 \%$ PFA, permeabilized with $0.3 \%$ saponin, and stained with the c-src antibody, followed by Alexa 555-conjugated anti-rabbit immunoglobulin (Ig) and DAPI. Scale bars, $5 \mu \mathrm{m}$. Coverslips were mounted using an anti-fade mounting medium (ProLong Gold-Invitrogen) on a glass slide. Fluorescent microscopy was performed on a ZEISS Axiovert 100 fluorescent microscope using the $63 \times$ Zeiss oil immersion objective. Single sections are shown for each condition. Images were processed with the use of Image pro-plus 4.5.1. (B) HVECs were treated as described above and lysates were loaded on the top of a $15-60 \%$ discontinuous sucrose gradient. Twelve fractions of equal volume were collected from the top (low density, fraction 1) to the bottom (high density, fraction 12). Samples were electrophoresed and analyzed by WB using anti-c-src and anti-FLCs antibody. (C) $10 \times 10^{6} \mathrm{HVECs}$ were incubated for $4 \mathrm{~h}$ at $37^{\circ} \mathrm{C}$ with $200 \mu \mathrm{g}$ MGUS and MM EVs pre-treated or not with a polyclonal anti-FLCs antibody (MM + sheep anti-FLCs), mouse anti-CD63 antibody ( $M M+m$ anti-CD63) or with $10 \mu \mathrm{g} / \mathrm{ml}$ heparin for $2 \mathrm{~h}$ at $4^{\circ} \mathrm{C}$ (MM + heparin). After incubation, cells were then washed with PBS $1 \times$ and treated with trypsin as described (5) and left in fresh starvation medium for $16 \mathrm{~h}$. Starvation medium was harvested, centrifuged at $800 \times g$ for $30 \mathrm{~min}, 16,000 \times g$ for $45 \mathrm{~min}$, and finally, ultra-centrifuged at $100,000 \times g$ for $2 \mathrm{~h}$ (see EVs Purification and Fractionation, Materials and Methods). WB analysis of cell extracts (homogenate, $\mathrm{H}, 30 \mu \mathrm{g}$ ) and pellets $(\mathrm{p}, 25 \mu \mathrm{l}$ ) were performed with anti-FLCs antibodies and with different vesicles markers (Lamp1, C-src, annexin V, and FLC). (D) c-src quantification in pellets after different treatments. Significant differences among the samples were determined with Student's $t$-test: ${ }^{*} p<0.05,{ }^{*} p<0.01,{ }^{* *} p<0.001$. Values were shown as mean values \pm SEM of at least three experiments. been studied in the modulation of tumor microenvironment. To test if the different intracellular uptake of MGUS and MM EVs and the diverse proliferation rates are directly linked, we sought some targeting molecules to be blocked in EVs docking and subsequent internalization. The presence of FLCs on the external surface of MM EVs (5) suggested us to test the cellular uptake after incubation of EVs with polyclonal antibodies against FLCs. Before cell treatment EVs were incubated with the specific Abs (anti-FLCs or anti-CD63) for $2 \mathrm{~h}$ and afterwards EVs were ultracentrifuged to separate unbound Abs. The pelleted EVs were added in the serum-free cell culture medium and intracellular uptake tested by immunofluorescence (Figure 3A) and flow-cytometry (Figure 3B). As shown in Figure 3A, the internalized EVs are clearly reduced after anti-FLCs treatment. Quantification of positive stained cells was significantly altered $(p<0.001)$ in comparison with MM EVs treated cells (Figure 3C). To confirm the confocal microscopy evidences we trypsinized cell monolayers after EVs intake and evaluated the PKH67 intensity versus positive CD31 staining by flow cytometry. Our data show that only few amounts of FLCs masked EVs are visible in the dot plot analysis of endothelial cells (Figure 3B). The same results were obtained with heparin pre-treated EVs but not with an anti-CD63 antibodies (Figures 3A-C). To investigate the active internalization of EVs and subsequent release of their content as a trigger factor of increased proliferation rates, we performed the proliferation assay with or without FLCs masked MM EVs (Figure 3D) on endothelial and myocardial cells and we could observe that masked MM EVs do not induce the same proliferation rate as MM EVs do.

\section{EVs INDUCED c-src RE-DISTRIBUTION AND NfKB NUCLEAR TRANSLOCATION ARE INTRACELLULAR UPTAKE DEPENDENT}

Endocytosis of monoclonal FLCs into the kidney proximal tubular epithelium promotes a c-src and $\mathrm{Nf} \kappa \mathrm{B}$ dependent generation of an intrarenal pro-inflammatory, profibrotic process (22). This pathway promotes the pro-inflammatory production of other cytokines, such as IL-6 enhancing kidney damage in MM (23-26). The presence of EVs containing FLCs in urine samples has also been published (27) suggesting that EVs are probably involved in different FLCs processing and subsequent inflammation pathways. To study the potential EVs induced pro-inflammatory response of endothelial cells, we treated HVECs with MGUS and MM EVs for $4 \mathrm{~h}$ at $37^{\circ} \mathrm{C}$. Afterwards, we performed an immunofluorescence assay (see Materials and Methods) to visualize c-src and NfкB intracellular distribution.

The intracellular c-src distribution was clearly altered after MM EVs exposure instead of MGUS EVs. Immunofluorescence analysis showed prevalent plasma membrane localization (Figure 4A). Sucrose gradient fractionation of the cell homogenates indicates a c-src re-distribution from lower to higher density fractions (Figure 4B) confirming the immunofluorescence data.

We previously published that (5) MM EVs are able to induce cellular ex novo secretion of c-src positive EVs, thus, we tested if anti-FLCs antibodies and heparin were both able to block the c-src decorated EVs production. We observed a striking reduction of csrc positive EVs generation and we could not see the same effect using a different target such as CD63 (Figures 4C,D).

To test the effect of MM EVs on NfאB, we treated HVECs with MGUS and MM EVs for $4 \mathrm{~h}$ at $37^{\circ} \mathrm{C}$ (Figure 5A). Only HVEC incubated with MM EVs showed a strong NfאB nuclear traslocation. The effect was completely abolished with MM EVs pre-treated with anti-FLCs antibodies and heparin. We quantified the nuclear $\mathrm{Nf \kappa B}$ fluorescent signal (Figure 5B) and we could observe that cells incubated with MM EVs showed a significant increase in comparison with other treatments. These data were also strongly confirmed by WB analysis of nuclear extracts (Figure 5C). To test the efficacy of the $\mathrm{Nf \kappa B}$ nuclear traslocation, we also compared our data with a TNF $\alpha$ pro-inflammatory treatment and with MM EVs pre-coated with the CD63 antibody: as expected we obtained a significant $\mathrm{Nf} \kappa \mathrm{B}$ nuclear traslocation compared to control cell (starvation) both in immunofluorescence and WB analysis (Figures 6A-C). To confirm that $\mathrm{Nf \kappa B}$ nuclear traslocation is specifically induced by MM EVs, we incubated HVECs with MM serum after the serial ultracentrifugation steps (SN3). Figures 6A-C show that this treatment do not significantly alter $\mathrm{Nf} \kappa \mathrm{B}$ intracellular distribution in comparison with control cells.

\section{DISCUSSION}

In the present study, we found that the intracellular uptake of serum MM EVs is enhanced in comparison to MGUS EVs. Our data show that MM EVs internalization is FLCs and GAGs mediated and we could demonstrate that MM EVs induce the $\mathrm{Nf \kappa B}$ nuclear translocation and the c-src kinase containing EVs generation. Blocking FLCs with anti-FLCs antibodies or masking the GAGs recognition with heparin altered the EVs intracellular 
A

$\mathrm{MM}$

MGUS

$\mathrm{MM}$

$+$

sh anti

FLCs

$\mathrm{MM}$

$\stackrel{+}{\stackrel{+}{\text { heparin }}}$
DAPI
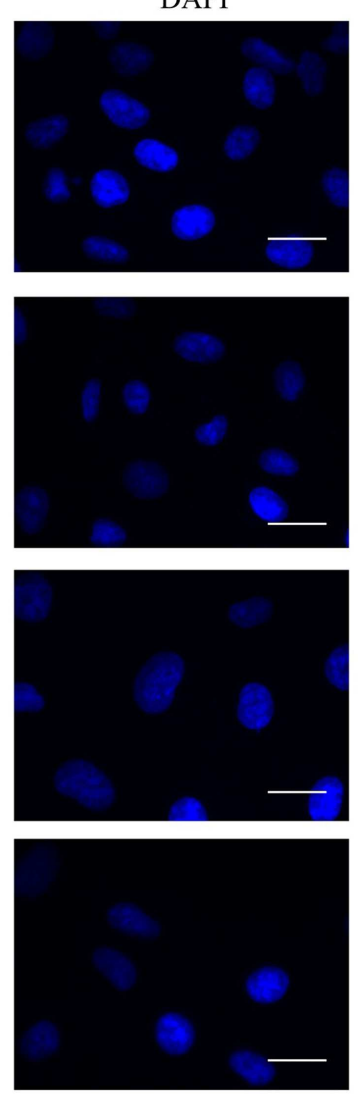

B

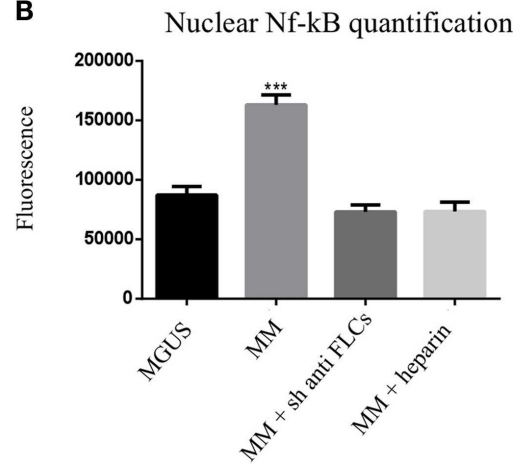

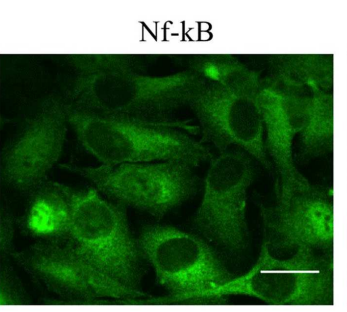
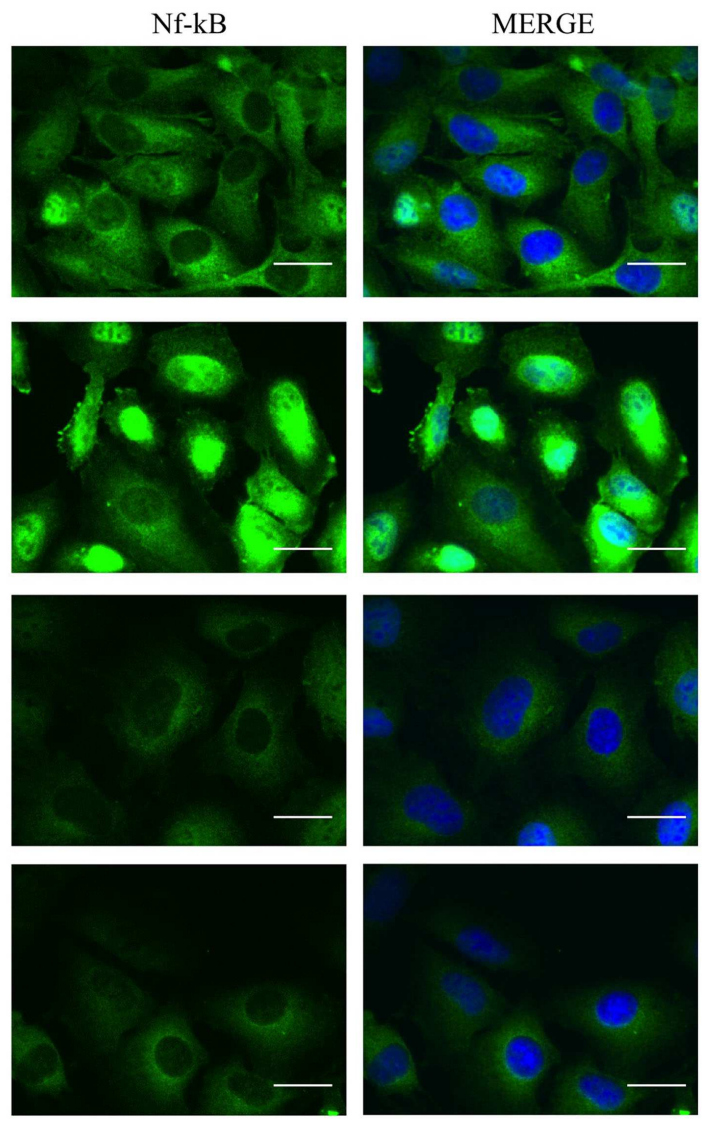

C

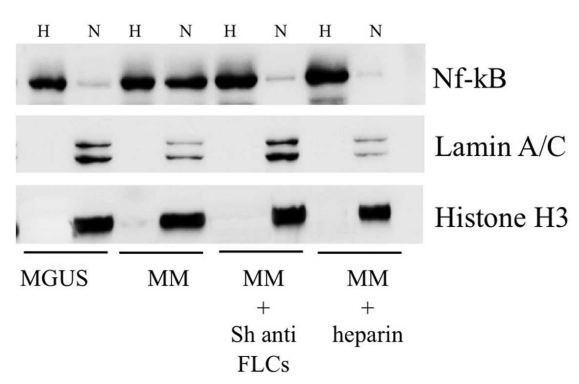

FIGURE 5 | Visualization of Nf $\mathrm{K} B$ nuclear traslocation (A) HVECs were treated with MGUS or MM serum EVs (200 $\mu \mathrm{g}$ of proteins) for $4 \mathrm{~h}$ at $\mathbf{3 7}^{\circ} \mathrm{C}$. Before cell treatment, MM EVs were incubated with anti-FLCs antibody (MM + sh anti FLC) or with $100 \mathrm{ng} / \mathrm{ml}$ of heparin (MM + heparin). After incubation, cells were washed with PBS $1 \times$ and fixed with $4 \%$ PFA, permeabilized with $0.2 \%$ Triton $\mathrm{X}-100,2 \mathrm{mg} / \mathrm{ml} \mathrm{BSA}, 1 \mathrm{mM} \mathrm{NaN} \mathrm{N}_{3}$ in PBS, and stained with anti-NfKB antibody, followed by Alexa 488-conjugated anti-rabbit immunoglobulin (lg) and DAPI. Scale bars, $5 \mu \mathrm{m}$. Coverslips were mounted using an anti-fade mounting medium (ProLong Gold-Invitrogen) on a glass slide. Fluorescent microscopy was performed on a ZEISS Axiovert 100 fluorescent microscope using the $63 \times$ Zeiss oil immersion objective. Single sections are shown for each condition. Images were processed with the use of Image pro-plus 4.5.1. (B) Nuclear $\mathrm{Nf} \kappa \mathrm{B}$ fluorescence intensity was measured after different treatments (100 cells each experimental point) using ImageJ program. Significant differences were determined with Student's $t$-test: ${ }^{*} p<0.05,{ }^{*} p<0.01$, ${ }^{* * *} p<0.001$. Values were shown as mean values \pm SEM of at least three experiments. (C) WB analysis of cell extracts (homogenate, $\mathrm{H}, 25 \mu \mathrm{g}$ ) and nuclear extract $(\mathrm{N}, 50 \mu \mathrm{g})$ were performed with anti-NfкB antibody and with different nuclear markers (Lamin A/C and Histone H3). uptake, the $\mathrm{Nf} \kappa \mathrm{B}$ nuclear translocation, and the c-src positive EVs secretion.

Extracellular vesicles involvement in hematologic malignancies such as MM is an emerging multifaceted tool for both diagnosis and therapy $(28,29)$. The evidences that cancer cells can modulate metastasis generation by increased and specific EVs secretion led to the investigation of the interaction between BM-MSC and MM cells. A mechanism that modulates MM tumor growth was 
A
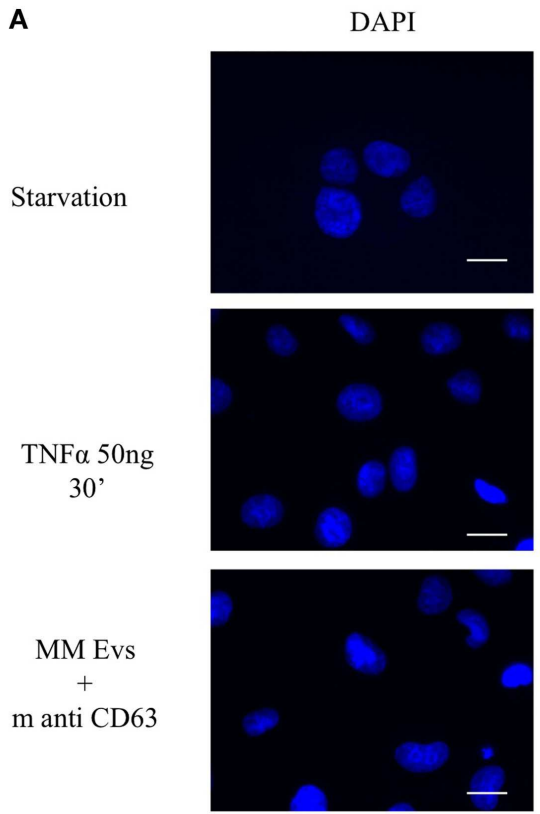

SN3 MM

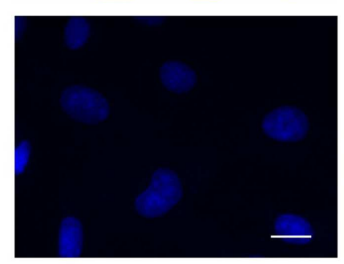

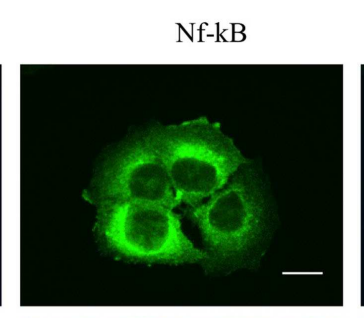
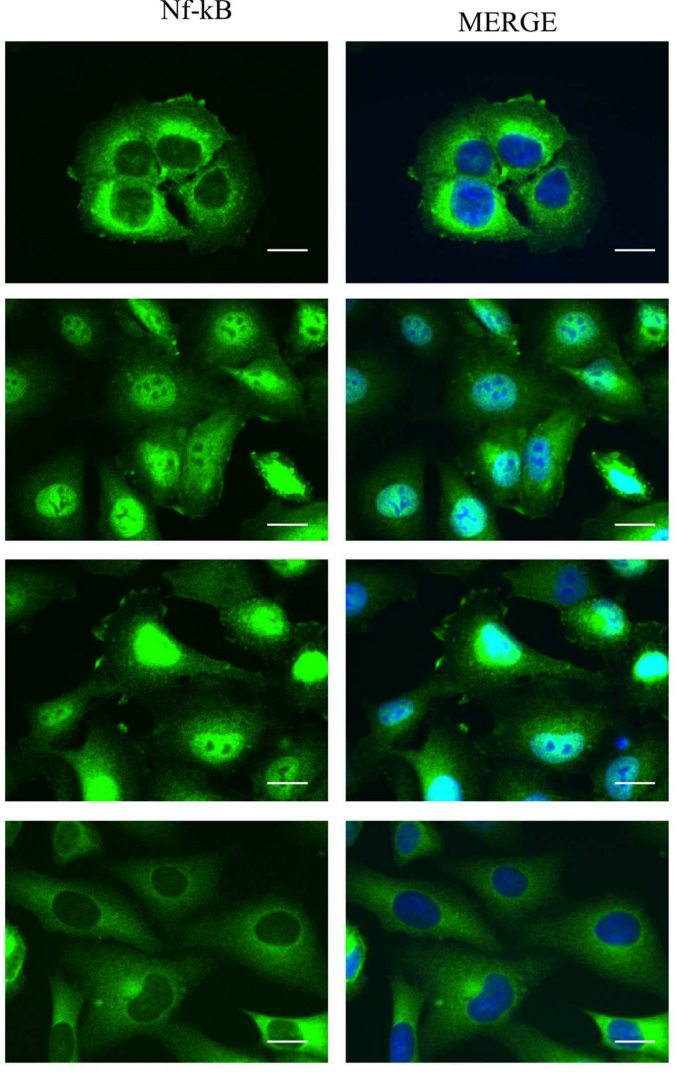
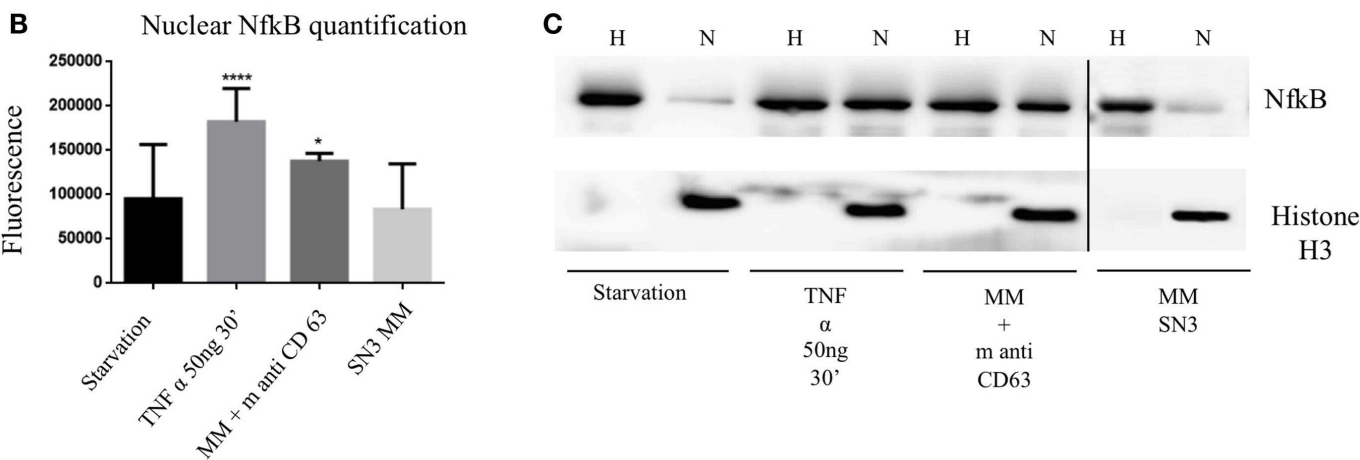

FIGURE 6 | Extracellular vesicles induce $\mathrm{Nf}_{\mathrm{K}} \mathrm{B}$ nuclear traslocation

(A) HVECs were treated with serum-free medium for $4 \mathrm{~h}$ (starvation), $10 \mathrm{ng} / \mathrm{ml} \mathrm{TNF}-\alpha$ for $30 \mathrm{~min}$, with MM EVs pre-incubated with anti-CD63 antibody (MM + $m$ anti-CD63) or with MM serum after serial ultracentrifugation steps (SN3 MM). Cells were fixed with 4\% PFA, permeabilized with $0.2 \%$ Triton $\mathrm{X}-100,2 \mathrm{mg} / \mathrm{ml} \mathrm{BSA}, 1 \mathrm{mM} \mathrm{NaN} \mathrm{N}_{3}$ in PBS, and stained with anti-NfKB antibody, followed by Alexa 488-conjugated anti-rabbit immunoglobulin (lg) and DAPI. Scale bars, $5 \mu \mathrm{m}$. Coverslips were mounted using an anti-fade mounting medium (ProLong Gold-Invitrogen) on a glass slide. Fluorescent microscopy was performed on a ZEISS Axiovert 100 fluorescent microscope using the $63 \times$ Zeiss oil immersion objective. Single sections are shown for each condition. Images were processed with the use of Image pro-plus 4.5.1. (B) Nuclear $\mathrm{Nf} \kappa \mathrm{B}$ fluorescence intensity was measured after different treatments (100 cells each experimental point) using ImageJ program. Significant differences were determined with Student's $t$-test: ${ }^{*} p<0.05,{ }^{* *} p<0.01$, ${ }^{* * *} p<0.001$. Values were shown as mean values \pm SEM of at least 3 experiments. (C) WB analysis of cell extracts (homogenate, $\mathrm{H}, 25 \mu \mathrm{g}$ ) and nuclear extract $(\mathrm{N}, 50 \mu \mathrm{g})$ were performed with anti-NfкB antibody and with anti-Histone 3 antibody. identified in the exosomal transfer from BM-MSCs to clonal plasma cells: MM BM-MSC-derived exosomes promoted MM tumor growth whereas normal BM-MSC exosomes inhibited the growth of MM cells (3).
We previously found that circulating EVs are significantly increased in MM patients in comparison to MGUS subjects and we identified the c-src kinase as a specific MM EVs marker (5). 
In the present work, we investigated the effect of circulating MM EVs on endothelial and myocardial cells: to this aim, we performed differential ultracentrifugation protocols for serum EVs purification. To be sure that small protein aggregates were removed we checked our EVs preparations with morphological assays, combining SEM and AFM.

Functional activities of EVs can be executed at different levels such as signaling through cell-surface receptors, transfer of signaling proteins, intracellular release of miRNA, mRNA, and DNA, or distribution of catalytic activities (30). Upon loading and release EVs are targeted to recipient cells in a not well understood fashion. Specific receptors or docking systems may contribute to the pathophysiology of tumor progression. Thus, we tested first of all the internalization rate of purified MGUS and MM serum EVs in endothelial and myocardial cells. We strikingly found that MM EVs are internalized while MGUS EVs are not, leading to the hypothesis that MM EVs can behave as signalosomes in the blood stream.

Heparan sulfate, proteoglycans have been shown to function as internalizing receptors of cancer cell-derived EVs (9) and are further involved in immunoglobulin FLCs amyloidogenesis (10). Because FLCs are actively internalized (31-33), we decided to test their involvement in EVs uptake together with GAGs and we found that both are responsible in efficient EVs uptake.

Nuclear factor kappa B transcription factors play a key role in the survival and proliferation of many kinds of B-cell tumors, including MM. It was shown that $\mathrm{Nf} \kappa \mathrm{B}$ activation in $\mathrm{MM}$ tumors results mainly from extrinsic signaling that stimulate receptors on normal plasma cells as well as on pre-malignant MGUS and MM tumors (34). The NfkB signaling has been rationalized in two independent signaling pathways, the canonical and not canonical that both induce $\mathrm{Nf} \kappa \mathrm{B}$ nuclear translocation and genes transcription. The Src-family kinases are also involved in such signaling cascades ultimately leading to cell survival and proliferation (35). Interestingly, $\mathrm{Nf \kappa B}$ is constitutively active in primary myeloma cells, and its blockade leads to apoptotic cell death (36).

In our investigation on the pathological effect of MM EVs, we found that they are capable to induce higher proliferation rates and to translocate the $\mathrm{Nf} \kappa \mathrm{B}$ into the nucleus. Blocking MM EVs uptake with polyclonal antibodies directed against FLCs or by EVs heparin coating clearly abolished the effect. Similar results were obtained after treating cells with the endocytosis inhibitor nocodazole (data not shown). It will be extremely interesting to test the relevance of EVs induced NfאB nuclear translocation in monitoring MGUS versus MM switching on a larger patient cohort. Further work is in progress to unravel the major EVs component involved in this signaling process. Our evidences that MM serum derived EVs contain the c-src kinase and generate new c-src positive vesicles in cultured cells suggest a potential "signalosomal" function of EVs in MM. The antitumor action of chemically modified heparins has been shown to inhibit myeloma growth and angiogenesis via disruption of the heparanase/syndecan-1 axis (37), and our data strongly confirm the usefulness of this therapeutic approach. The evidence that we saw on FLCs involvement in EVs uptake open a new door for combined therapeutic approaches, particularly in patients with FLCs induced kidney failure or amyloidosis.
Multiple myeloma is one of the most frequent hematological malignancies and combined therapeutic approaches are needed to ameliorate the life expectancy of MM patients.

Our study shows for the first time that FLCs are involved in EVs intracellular uptake and confirm that GAGs are also involved in tumor derived EVs processing. The $\mathrm{Nf} \kappa \mathrm{B}$ nuclear translocation after MM EVs exposure demonstrate the transactivating role of EVs in cancer and our discovery that anti-FLCs antibodies and heparin are able to block this pathway open new insights in EVs cellular biology, MM therapeutic and diagnostic approaches.

\section{AUTHOR CONTRIBUTIONS}

Doris Ricotta, Giuseppe Di Noto conceived and designed the experiments. Giuseppe Di Noto, Marco Chiarini, Lucia Paolini, Elena Laura Mazzoldi, and Viviana Giustini performed the experiments. Giuseppe Di Noto, Lucia Paolini, and Annalisa Radeghieri were involved in samples recruitment. Doris Ricotta, Giuseppe Di Noto, Marco Chiarini, Lucia Paolini, Viviana Giustini, Luigi Caimi, and Annalisa Radeghieri analyzed the data. Doris Ricotta and Giuseppe Di Noto wrote the first draft of the manuscript. All authors reviewed and edited the manuscript and approved the final version of the manuscript.

\section{ACKNOWLEDGMENTS}

We would like to thank "The Binding site Italy" for providing us the anti-FLCs antibodies. We thank Davide Dallatana, Paolo Bergese and Andrea Zendrini for SEM and AFM consulting. This work was supported by University of Brescia Research found (ex 60\%) and "Prima spes onlus" foundation. The funders had no role in study design, data collection and analysis, decision to publish, or preparation of the manuscript.

\section{REFERENCES}

1. Valadi H, Ekström K, Bossios A, Sjöstrand M, Lee JJ, Lötvall JO. Exosomemediated transfer of mRNAs and microRNAs is a novel mechanism of genetic exchange between cells. Nat Cell Biol (2007) 9(6):654-9. doi:10.1038/ncb1596

2. Atay S, Godwin AK. Tumor-derived exosomes: a message delivery system for tumor progression. Commun Integr Biol (2014) 7(1):e28231. doi:10.4161/cib. 28231

3. Roccaro AM, Sacco A, Maiso P, Azab AK, Tai YT, Reagan M, et al. BM mesenchymal stromal cell-derived exosomes facilitate multiple myeloma progression. J Clin Invest (2013) 123(4):1542-55. doi:10.1172/JCI66517

4. Harshman SW, Canella A, Ciarlariello PD, Rocci A, Agarwal K, Smith EM, et al. Characterization of multiple myeloma vesicles by label-free relative quantitation. Proteomics (2013) 13(20):3013-29. doi:10.1002/pmic.201300142

5. Di Noto G, Paolini L, Zendrini A, Radeghieri A, Caimi L, Ricotta D. c-src enriched serum microvesicles are generated in malignant plasma cell dyscrasia. PLoS One (2013) 8(8):e70811. doi:10.1371/journal.pone.0070811

6. Coluccia AM, Cirulli T, Neri P, Mangieri D, Colanardi MC, Gnoni A, et al. Validation of PDGFRbeta and c-src tyrosine kinases as tumor/vessel targets in patients with multiple myeloma: preclinical efficacy of the novel, orally available inhibitor dasatinib. Blood (2008) 112:1346-56. doi:10.1182/blood-2007-10-116590

7. Sandur SK, Pandey MK, Sung B, Aggarwal BB. 5-Hydroxy-2-methyl-1,4naphthoquinone, a vitamin K3 analogue, suppresses STAT3 activation pathway through induction of protein tyrosine phosphatase, SHP-1: potential role in chemosensitization. Mol Cancer Res (2010) 8:107-18. doi:10.1158/1541-7786. MCR-09-0257

8. Feng D, Zhao WL, Ye YY, Bai XC, Liu RQ, Chang LF, et al. Cellular internalization of exosomes occurs through phagocytosis. Traffic (2010) 11:675-87. doi:10.1111/j.1600-0854.2010.01041.x

9. Christianson HC, Svensson KJ, van Kuppevelt TH, Li JP, Belting M. Cancer cell exosomes depend on cell-surface heparan sulfate proteoglycans for 
their internalization and functional activity. Proc Natl Acad Sci U S A (2013) 110(43):17380-5. doi:10.1073/pnas.1304266110

10. Jiang X, Myatt E, Lykos P, Stevens FJ. Interaction between glycosaminoglycans and immunoglobulin light chains. Biochemistry (1997) 36(43):13187-94. doi:10.1021/bi970408h

11. Ramani VC, Sanderson RD. Chemotherapy stimulates syndecan-1 shedding: a potentially negative effect of treatment that may promote tumor relapse. Matrix Biol (2014) 35:215-22. doi:10.1016/j.matbio.2013.10.005

12. Sanderson RD, Yang Y. Syndecan-1: a dynamic regulator of the myeloma microenvironment. Clin Exp Metastasis (2008) 25:149-59. doi:10.1007/s10585007-9125-3

13. Sanderson RD, Yang Y, Suva LJ, Kelly T. Heparan sulfate proteoglycans and heparanase-partners in osteolytic tumor growth and metastasis. Matrix Biol (2004) 23:341-52. doi:10.1016/j.matbio.2004.08.004

14. Thompson CA, Purushothaman A, Ramani VC, Vlodavsky I, Sanderson RD. Heparanase regulates secretion, composition, and function of tumor cell-derived exosomes. J Biol Chem (2013) 288(14):10093-9. doi:10.1074/jbc.C112.444562

15. Savina A, Vidal M, Colombo MI. The exosome pathway in K562 cells is regulated by Rab11. J Cell Sci (2002) 115(Pt 12):2505-15.

16. Ho IK, Ellman GL. Triton solubilized acetylcholinesterase of brain. J Neurochem (1969) 16(11):1505-13. doi:10.1111/j.1471-4159.1969.tb09905.x

17. Zadeh MS, Kolb JP, Geromin D, D’Anna R, Boulmerka A, Marconi A, et al. Regulation of ICAM-1/CD54 expression on human endothelial cells by hydrogen peroxide involves inducible NO synthase. J Leukoc Biol (2000) 67(3):327-34.

18. dos Santos T, Varela J, Lynch I, Salvati A, Dawson KA. Effects of transport inhibitors on the cellular uptake of carboxylated polystyrene nanoparticles in different cell lines. PLoS One (2011) 6(9):e24438. doi:10.1371/journal.pone. 0024438

19. Raposo G, Stoorvogel W. Extracellular vesicles: exosomes, microvesicles, and friends. J Cell Biol (2013) 200(4):373-83. doi:10.1083/jcb.201211138

20. Masyuk AI, Huang BQ, Ward CJ, Gradilone SA, Banales JM, Masyuk TV, et al. Biliary exosomes influence cholangiocyte regulatory mechanisms and proliferation through interaction with primary cilia. Am J Physiol Gastrointest Liver Physiol (2010) 299(4):G990-9. doi:10.1152/ajpgi.00093.2010

21. Falk RH, Comenzo RL, Skinner M. The systemic amyloidosis. N Engl J Med (1997) 337(13):898-909. doi:10.1056/NEJM199709253371306

22. Wei-Zhong Y, Pei-Xuan W, Kristal JA, Basnayake K, Sanders PW. Immunoglobulin light chains activate nuclear factor- $\mathrm{KB}$ in renal epithelial cells through a Srcdependent mechanism. Blood (2011) 117(4):1301-7. doi:10.1182/blood-201008-302505

23. Basnayake K, Ying WZ, Wang PX, Sanders PW. Immunoglobulin light chains activate tubular epithelial cells through redox signaling. J Am Soc Nephrol (2010) 21(7):1165-73. doi:10.1681/ASN.2009101089

24. Sengul S, Zwizinski C, Simon EE, Kapasi A, Singhal PC, Batuman V. Endocytosis of light chains induces cytokines through activation of NF-kappaB in human proximal tubule cells. Kidney Int (2002) 62(6):1977-88. doi:10.1046/j. 1523- 1755.2002.00660.x

25. Sengul S, Zwizinski C, Batuman V. Role of MAPK pathways in light chaininduced cytokine production in human proximal tubule cells. Am J Physiol Renal Physiol (2003) 284(6):F1245-54.

26. Arimura A, Li M, Batuman V. Potential protective action of pituitary adenylate cyclase-activating polypeptide (PACAP38) on in vitro and in vivo models of myeloma kidney injury. Blood (2006) 107(2):661-8. doi:10.1182/blood-200503-1186
27. Ramirez-Alvarado M, Ward CJ, Huang BQ, Gong X, Hogan MC, Madden BJ, et al. Differences in immunoglobulin light chain species found in urinary exosomes in light chain amyloidosis (AL). PLoS One (2012) 7(6):e38061. doi:10.1371/journal.pone.0038061

28. Revenfeld AL, Bæk R, Nielsen MH, Stensballe A, Varming K, Jørgensen M. Diagnostic and prognostic potential of extracellular vesicles in peripheral blood. Clin Ther (2014) 36(6):830-46. doi:10.1016/j.clinthera.2014.05.008

29. Yousefpour P, Chilkoti A. Co-opting biology to deliver drugs. Biotechnol Bioeng (2014) 111(9):1699-716. doi:10.1002/bit.25307

30. Christianson HC, Svensson KJ, Belting M. Exosome and microvesicle mediated phene transfer in mammalian cells. Semin Cancer Biol (2014) 28C:31-8. doi:10.1016/j.semcancer.2014.04.007

31. Butch AW, Kelly KA, Munshi NC. Dendritic cells derived from multiple myeloma patients efficiently internalize different classes of myeloma protein. Exp Hematol (2001) 29(1):85-92. doi:10.1016/S0301-472X(00)00619-6

32. Monis GF, Schultz C, Ren R, Eberhard J, Costello C, Connors L, et al. Role of endocytic inhibitory drugs on internalization of amyloidogenic light chains by cardiac fibroblast. Am J Pathol (2006) c169(6):1939-52. doi:10.2353/ajpath. 2006.060183

33. Teng J, Russell WJ, Gu X, Cardelli J, Jones ML, Herrera GA. Different types of glomerulopathic light chains interact with mesangial cells using a common receptor but exhibit different intracellular trafficking patterns. Lab Invest (2004) 84(4):440-51. doi:10.1038/labinvest.3700139

34. Demchenko YN, Kuehl WM. A critical role for the NfkB pathway in multiple myeloma. Oncotarget (2010) 1(1):59-68.

35. Gasparini C, Celeghini C, Monasta L, Zauli G. NF-кB pathways in hematological malignancies. Cell Mol Life Sci (2014) 71(11):2083-102. doi:10.1007/s00018013-1545-4

36. Demchenko YN, Brents LA, Li Z, Bergsagel LP, McGee LR, Kuehl MW. Novel inhibitors are cytotoxic for myeloma cells with NFkB inducing kinase-dependent activation of NFkB. Oncotarget (2014) 5(12):4554-66

37. Ritchie JP, Ramani VC, Ren Y, Naggi A, Torri G, Casu B, et al. SST0001, a chemically modified heparin, inhibits myeloma growth and angiogenesis via disruption of the heparanase/syndecan-1 axis. Clin Cancer Res (2011) 17(6):1382-93. doi:10.1158/1078-0432.CCR-10-2476

Conflict of Interest Statement: The authors declare that the research was conducted in the absence of any commercial or financial relationships that could be construed as a potential conflict of interest.

Received: 15 July 2014; accepted: 04 October 2014; published online: 27 October 2014. Citation: Di Noto G, Chiarini M, Paolini L, Mazzoldi EL, Giustini V, Radeghieri A, Caimi L and Ricotta D (2014) Immunoglobulin free light chains and GAGs mediate multiple myeloma extracellular vesicles uptake and secondary $N f \kappa B$ nuclear translocation. Front. Immunol. 5:517. doi: 10.3389/fimmu.2014.00517

This article was submitted to Immunotherapies and Vaccines, a section of the journal Frontiers in Immunology.

Copyright ( 2014 Di Noto, Chiarini, Paolini, Mazzoldi, Giustini, Radeghieri, Caimi and Ricotta. This is an open-access article distributed under the terms of the Creative Commons Attribution License (CC BY). The use, distribution or reproduction in other forums is permitted, provided the original author(s) or licensor are credited and that the original publication in this journal is cited, in accordance with accepted academic practice. No use, distribution or reproduction is permitted which does not comply with these terms. 